Abstracta Iranica Abstracta Iranica

Revue bibliographique pour le domaine irano-aryen

Volume 28 | 2007

Comptes rendus des publications de 2005

\title{
Modern Persian. A Course-book. London and New York, Routledge Curzon, 2005, 259 p.
}

\section{Pollet Samvelian}

\section{(2) OpenEdition}

1 Journals

\section{Édition électronique}

URL : http://journals.openedition.org/abstractairanica/10272

DOI : 10.4000/abstractairanica. 10272

ISSN : 1961-960X

Éditeur :

CNRS (UMR 7528 Mondes iraniens et indiens), Éditions de l'IFRI

Édition imprimée

Date de publication : 15 mai 2007

ISSN : 0240-8910

Référence électronique

Pollet Samvelian, «Modern Persian. A Course-book. London and New York, Routledge Curzon, 2005, 259 p. », Abstracta Iranica [En ligne], Volume 28 | 2007, document 28, mis en ligne le 18 septembre 2007, consulté le 25 septembre 2020. URL : http://journals.openedition.org/abstractairanica/10272 ; DOI : https://doi.org/10.4000/abstractairanica.10272

Ce document a été généré automatiquement le 25 septembre 2020.

Tous droits réservés 


\title{
Modern Persian. A Course-book. London and New York, Routledge Curzon, 2005, 259 p.
}

\author{
Pollet Samvelian
}

1 Ce manuel, destiné aux débutants, est le fruit de trois années d'expérience d'enseignement de l'A. à l'Université d'Edinbourg. Il est organisé en dix-sept leçons, comprenant chacune un vocabulaire, quelques points de grammaire, un texte ou un dialogue et des exercices. Le registre retenu est le persan soutenu ou standard. Toutefois, un appendice de cinq pages intitulé «colloquial Persian» fournit une liste sommaire de différences de prononciation entre le persan standard ou soutenu et le persan familier. Le vocabulaire introduit au fil des leçons est réuni en un glossaire à la fin de l'ouvrage. L'ouvrage est accompagné en outre de supports audio (sous forme de CD).

2 L'A. a fait le choix de confronter d'emblée l'apprenant à l'écriture du persan. Par conséquent, les exemples et les textes ne font pas l'objet de transcriptions phonétiques, ni de translittérations. Comme les voyelles «brèves" ou "instables" sont systématiquement notées pour chaque mot pris isolément, l'absence de transcription phonétique ne pose pas de problème particulier. En revanche, le fait que l'ed̄âfe ne soit jamais noté est problématique à plusieurs titres. Pour ne prendre qu'un exemple, dans les séquences lexicalisées qui fonctionnent comme des mots composés, la présence ou l'absence de l'ed̄āfe n'est a priori pas prévisible, komak-e mālī (avec e ẹāfe) s'opposant ainsi à doHtar Huăle (sans eḍâfe). Ces informations n'étant pas à la portée de l'apprenant débutant, la voyelle eḍāfe aurait dû être systématiquement notée à l'instar des autres voyelles « brèves".

3 En ce qui concerne le contenu, on regrettera que la prosodie (intonation et accentuation) soit la grande absente de ce manuel d'introduction au persan. Signalons également quelques autres omissions ou problèmes. A titre d'exemple, les indications concernant l'usage de l'enclitique indéfini - $i$ sont extrêmement laconiques et peuvent induire l'apprenant en erreur. Par ailleurs, même si le registre retenu n'est pas le 
persan familier, l'A. aurait néanmoins pu mentionner quelques tournures extrêmement fréquentes dans la langue courante, telles l'utilisation des classifieurs avec les noms (ex. tā, nafar).

INDEX

Thèmes : 2.2. Langues vivantes et dialectes

\section{AUTEURS}

POLLET SAMVELIAN

CNRS / Mondes iranien et indien - Paris 